G. Doronzo • I. Russo • L. Mattiello •

C. Riganti - G. Anfossi - M. Trovati

\title{
Insulin activates hypoxia-inducible factor-1 $\alpha$ in human and rat vascular smooth muscle cells via phosphatidylinositol-3 kinase and mitogen-activated protein kinase pathways: impairment in insulin resistance owing to defects in insulin signalling
}

\author{
Received: 25 July 2005 / Accepted: 17 November 2005 / Published online: 28 February 2006
}

(C) Springer-Verlag 2006

\begin{abstract}
Aims/hypothesis: We previously demonstrated that insulin stimulates vascular endothelial growth factor (VEGF) synthesis and secretion via phosphatidylinositol-3 kinase (PI3-K) and mitogen-activated protein kinase (MAPK) pathways in vascular smooth muscle cells (VSMC) from humans and from insulin-sensitive lean Zucker $\mathrm{fa} /+$ rats. We also showed that this effect is attenuated in VSMC from insulin-resistant obese Zucker $f a / f a$ rats. As it is not known whether the effects of insulin on VEGF involve activation of hypoxia-inducible factor-1 (HIF-1), we aimed to evaluate: (1) whether insulin modulates HIF- $1 \alpha$ protein synthesis and activity; (2) the insulin signalling pathways involved; and (3) the role of insulin resistance. Methods: Using aortic VSMC taken from humans and Zucker rats and cultured in normoxia, the following were evaluated: (1) dose-dependent $(0.5,1$, $2 \mathrm{nmol} / \mathrm{l})$ and time-dependent $(2,4,6 \mathrm{~h})$ effects exerted by insulin on HIF- $1 \alpha$ content in both nucleus and cytosol, measured by Western blots; (2) insulin effects on HIF-1 DNA-binding activity on the $V E G F$ gene, measured by electrophoretic mobility shift assay; and (3) involvement of the insulin signalling molecules in these insulin actions, by using the following inhibitors: LY294002 (PI3-K), PD98059 (extracellular signal regulated kinase [ERK]),
\end{abstract}

Electronic Supplementary Material Supplementary material is available in the online version of this article at http://dx. doi.org/10.1007/s00125-006-0156-0

G. Doronzo · I. Russo - L. Mattiello

G. Anfossi $\cdot$ M. Trovati $(\bowtie)$

Diabetes Unit, Department of Clinical and Biological Sciences,

University of Turin, San Luigi Gonzaga Hospital,

I-10043 Orbassano, Turin, Italy

e-mail: mariella.trovati@unito.it

Tel.: +39-0119026612

Fax: +39-0119038639

C. Riganti

Department of Genetics, Biology and Medical Chemistry,

University of Turin, Turin, Italy
SP600125 (Jun N terminal kinase [JNK]), SB203580 (p38 mitogen-activated protein kinase) and rapamycin (mammalian target of rapamycin), and by detecting the insulin signalling molecules by Western blots. Results: In aortic VSMC from humans and Zucker $f a /+$ rats cultured in normoxia insulin increases the HIF- $1 \alpha$ content in cytosol and nucleus via dose- and time-dependent mechanisms, and HIF-1 DNA-binding activity on the VEGF gene. The insulin-induced increase of HIF-1 $\alpha$ is blunted by the translation inhibitor cycloheximide, LY294002, PD98059, SP600125 and rapamycin, but not by SB203580. It is also reduced in Zucker $f a / f a$ rats, which present an impaired ability of insulin to induce Akt, ERK-1/2 and JNK-1/2 phosphorylation. Conclusions/interpretation: These results provide a biological mechanism for the impaired collateral vessel formation in obesity.

Keywords c-Jun N-terminal kinase · Hypoxia-inducible factor - Insulin · Insulin resistance - Mitogen-activated protein kinase - Obesity - Phosphatidylinositol-3 kinase . Vascular endothelial growth factor - Vascular smooth muscle $\cdot$ Zucker rats

Abbreviations EMSA: Electrophoretic mobility shift assay - ERK: Extracellular signal-regulated kinase - ESM: Electronic supplementary material - HIF: Hypoxiainducible factor - HRE: Hypoxia response element - JNK: c-Jun N-terminal kinase - MAPK: Mitogen-activated protein kinase - mTOR: Mammalian target of rapamycin . PI3-K: Phosphatidylinositol-3 kinase - siRNA: Silencing RNA - VEGF: Vascular endothelial growth factor - VSMC: Vascular smooth muscle cells

\section{Introduction}

Obese subjects affected by ischaemic heart disease present a poorer collateral vessel development than non-obese subjects with a similar number of diseased vessels, degree of coronary artery stenosis, sex, age and duration of angina 
symptoms [1]. Also, body mass index independently influences the degree of collateral development in patients with coronary artery disease [1]. Impairment of vascular endothelial growth factor (VEGF) synthesis/action could play a role in this phenomenon, as observed in insulinresistant rats [2].

In vascular smooth muscle cells (VSMC) insulin increases VEGF mRNA expression [3] and protein synthesis [4] via both phosphatidylinositol 3-kinase (PI3-K) and mitogen-activated protein kinase (MAPK) pathways [3, 4]. This insulin effect is blunted in obese, insulin-resistant Zucker $f a / f a$ rats [4], which represent an animal model of insulin resistance [5]. It is not known whether insulin acts on the $V E G F$ gene directly or via the transcription factor hypoxia-inducible factor-1 (HIF-1), named for its ability to mediate cellular adaptation to oxygen deficiency $[6,7]$.

HIF-1 is a 'master switch' protein generated in response to hypoxia, able to bind about 60 genes, and to influence biological events relating to erythropoiesis, vasomotion, glucose metabolism, cell proliferation/survival, iron metabolism and angiogenesis. VEGF is one of its target genes $[6,7]$. HIF-1 is composed of an $\alpha$-subunit and a $\beta$-subunit $[6,7]$. HIF- $1 \beta$ is a constitutively expressed nuclear translocator protein which binds HIF- $1 \alpha$ and allows it to exert its transcriptional effects, whereas HIF- $1 \alpha$ is a cytosolic protein able to translocate to the nucleus where it associates with HIF-1 $\beta$ and binds to a consensus sequence present in the hypoxia response element (HRE) in the promoters of the oxygen-controlled target genes, thus inducing their expression $[6,7]$.

In normoxic conditions, HIF- $1 \alpha$ undergoes ubiquitination followed by rapid proteolytic destruction and inhibition of transcriptional activity; hypoxia blunts its ubiquitin/ proteasome-mediated degradation thus increasing HIF- $1 \alpha$ stability, nuclear translocation and activity $[6,7]$. The HIF1 system is also induced in normoxia by cytokines and growth factors, including insulin, insulin-like growth factors, transforming growth factor, platelet-derived growth factor, epidermal growth factor and interleukin$1 \beta[6,7]$. These compounds induce HIF- $\alpha$ synthesis with mechanisms involving both the PI3-K and MAPK pathways $[6,7]$.

Insulin stimulates HIF- $1 \alpha$ in different cell types, such as human hepatocellular carcinoma cells, rat skeletal muscle myoblasts, rat hepatoma cells and human ductal breast carcinoma cells [8]; insulin-induced stimulation of HIF-1 $\alpha$ mediated by PI3-K has been demonstrated in human prostate carcinoma cells [9], retinal epithelial cells [10], and human hepatoma cells [11]. Finally, acute insulin therapy exacerbates diabetic blood-retinal barrier breakdown via activation of the HIF- $1 \alpha /$ VEGF pathway [12]. HIF- $1 \beta$ is constitutively present in the nucleus, and is not modulated by growth factors, in particular by insulin and insulin-like growth factor-1 [13]. The role of insulin in the modulation of HIF- $1 \alpha$ protein synthesis and activity in VSMC and the putative changes of the insulin/HIF-1 pathway in insulin resistance states have not been clarified as yet. On the other hand, in these cells, the HIF-1 system is expressed and induced not only by hypoxia [14], but also by angiotensin-II, thrombin and platelet-derived growth factor in normoxia [15].

To evaluate whether HIF-1 mediates the insulin-induced VEGF synthesis and secretion that were observed in VSMC [4], we designed the present study. It aimed to clarify whether in aortic VSMC insulin influences HIF- $1 \alpha$ protein content in the cytosol and in the nucleus, and HIF- $1 \alpha$ binding to the HRE on the VEGF gene. We also sought to determine whether the insulin effects on HIF- $1 \alpha$ are mediated by protein synthesis, involve PI3-K and/or MAPK pathways, and are preserved in aortic VSMC from obese, insulin-resistant Zucker $f a / f a$ rats, in which we previously described a defective insulin-induced VEGF synthesis and secretion [4]. We also assessed the insulin signalling differences in VSMC from insulin-sensitive and insulin-resistant Zucker rats.

\section{Materials and methods}

\section{Research design}

Experiments were carried out in normoxic conditions in cultured aortic VSMC derived from humans and from lean, insulin-sensitive Zucker $\mathrm{fa} /+$ and obese, insulin-resistant Zucker $f a / f a$ rats.

To evaluate whether insulin modulates the cytosolic and nuclear content of HIF- $1 \alpha$ time- and dose-dependently Western blots were carried out in VSMC incubated for 2, 4 or $6 \mathrm{~h}$ with $2 \mathrm{nmol} / \mathrm{l}$ human regular insulin. Dosedependence experiments were carried out by incubating VSMC with $0.5,1$ or $2 \mathrm{nmol} / 1$ insulin for $6 \mathrm{~h}$.

To evaluate whether the insulin effects on HIF- $1 \alpha$ depend on increased protein synthesis, experiments were repeated in the presence of a 60 -min preincubation with the translation inhibitor cycloheximide $(10 \mu \mathrm{g} / \mathrm{ml})$.To identify the insulin signalling molecules involved, experiments were repeated in the presence of a 60 -min preincubation with the PI3-K inhibitor LY294002 $(100 \mu \mathrm{mol} / \mathrm{l})$, the extracellular signal-regulated kinase (ERK) inhibitor PD98059 (30 $\mu \mathrm{mol} /$ 1); c-Jun N-terminal kinase (JNK) inhibitor SP600125 $(30 \mu \mathrm{mol} / \mathrm{l})$; p38 MAPK inhibitor SB203580 $(10 \mu \mathrm{mol} / \mathrm{l})$ and rapamycin $(20 \mathrm{nmol} / \mathrm{l})$, an inhibitor of mammalian target of rapamycin (mTOR), a molecule downstream to Akt in the insulin signalling cascade.

To evaluate whether insulin influences HIF- $1 \alpha$ binding to HRE on the VEGF gene, VSMC nuclear proteins were submitted to electrophoretic mobility shift assay (EMSA) with a supershift analysis after a 6-h incubation with $2 \mathrm{nmol} / \mathrm{l}$ human regular insulin.

To evaluate whether the insulin influence on VEGF expression depends on HIF- $1 \alpha$ activation, VSMC were incubated for $8 \mathrm{~h}$ with $2 \mathrm{nmol} / 1$ human regular insulin with or without HIF- $1 \alpha$ mRNA silencing. 
To confirm the data obtained by insulin signalling inhibitors, we studied the ability of insulin to induce phosphorylation of Akt, ERK-1, ERK-2, JNK-1, JNK-2, and p70S6K, a target of mTOR.

Experiments were carried out following the Principles of Laboratory Animal Care (NIH publication no.85-23, revised 1985) and were approved by our Institutional Ethical Committee.

Chemicals

Human recombinant insulin was obtained from Lilly (Lilly France, Saint Cloud, Paris, France); $\mathrm{CoCl}_{2}, \mathrm{LY} 294002$ hydrochloride, PD98059, cycloheximide, rapamycin, SP600125, SB203580 were from Sigma-Aldrich (St Louis, MO, USA). The compounds used for Western blots, EMSA and silent RNA (siRNA) transfection are detailed below.
Cell culture and characterisation and preparation of cytosolic and nuclear cell extracts

Experiments were carried out on human aortic VSMC (Cambrex Bio Science, Milan, Italy) and on VSMC derived from the aortas of Zucker $f a /+$ and $f a / f a$ rats isolated and cultured in our laboratory. The Zucker rats were purchased from Charles River Laboratories Italy (Calco, Italy), fed with standard rodent chow and water ad libitum and killed with $\mathrm{CO}_{2}$ after a 12-h fast when they were 14 weeks old: the aorta was removed immediately after death. VSMC isolation and characterisation were performed according to classical procedures [16] as previously reported $[4,17]$.

VSMC at the sixth and seventh passages were cultured in minimal essential medium (MEM) with $10 \%$ FCS until they reached about $80 \%$ confluence to prepare cytosolic and nuclear extracts as described in the Electronic Supplementary Material (ESM).
Fig. 1 Western immunoblottings and their densitometric analysis showing: (1) the timedependent effects on HIF-1 $\alpha$ protein cytosolic content (a) and nuclear content (b) elicited by $2 \mathrm{nmol} / 1$ insulin incubation for 2,4 and $6 \mathrm{~h}$ in human VSMC $(n=6$, ANOVA $p=0.0001)$; and (2) the dose-dependent effects on HIF- $1 \alpha$ protein cytosolic content (c) and nuclear content (d) elicited by $6 \mathrm{~h}$ of incubation with insulin $0.5,1$ and $2 \mathrm{nmol} / 1$ in human VSMC $(n=6$, ANOVA $p=0.0001$ ). Loading control: $\alpha$-Actin and histone H4. Open bars, control; closed bars, insulin. Blots are representative of six experiments a
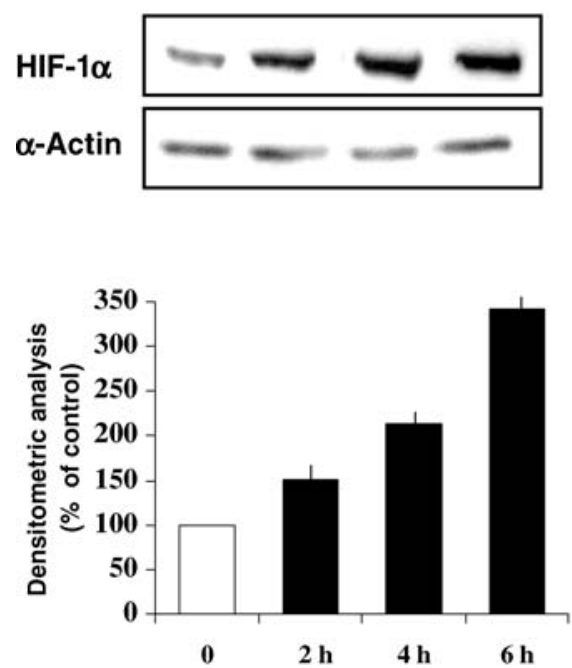

C
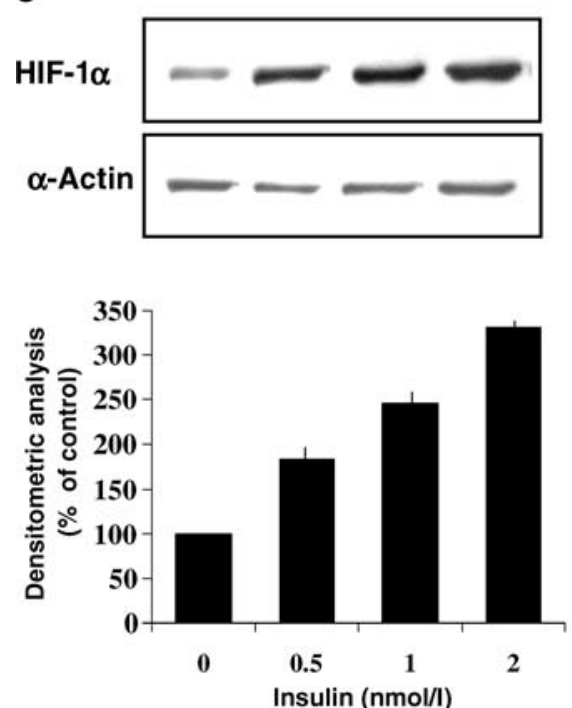

b
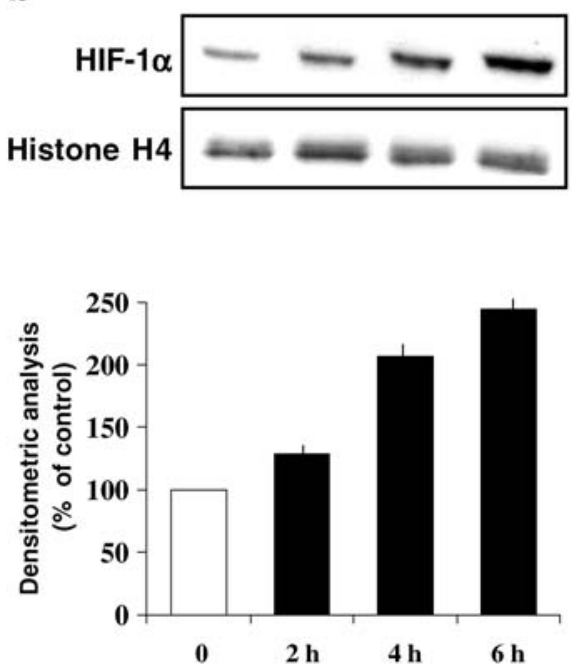

d
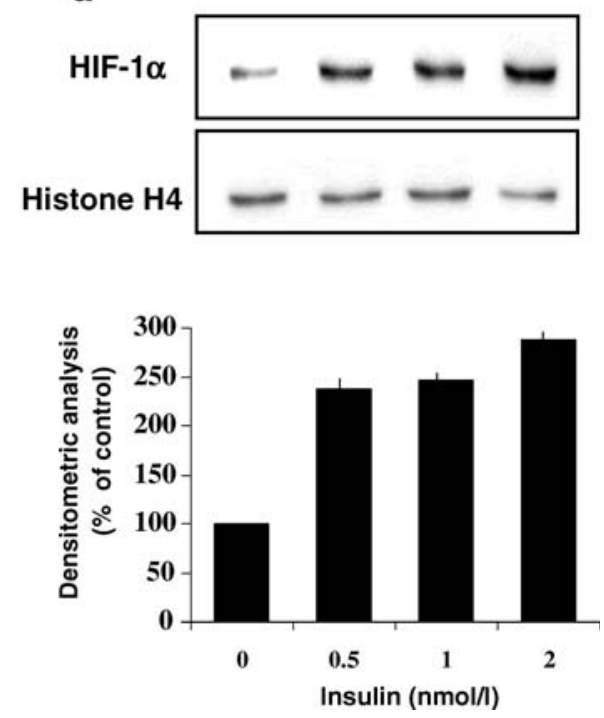


\section{Western blot analysis}

To measure HIF- $1 \alpha$, VEGF, and some molecules involved in the insulin signalling pathway (i.e. phosphorylated and non-phosphorylated Akt, ERK-1, ERK-2, JNK-1, JNK-2 and p70S6K) VSMC extracts $(20 \mu \mathrm{g})$ were separated by $8 \%$ SDS-PAGE and transferred to Immobilon-P Transfer Membranes (Millipore Co, Bedford, MA, USA). Membranes were incubated for $60 \mathrm{~min}$ with monoclonal antibodies against all the previously quoted molecules (Santa Cruz Biotechnology, Santa Cruz, CA, USA) in PBS containing $0.1 \%$ Tween-20 (Sigma-Aldrich). Western blots were carried out as previously described [4] and detailed in ESM.

As a positive control, we measured HIF- $1 \alpha$ nuclear and cytosolic concentrations after a 6-h incubation with $200 \mu \mathrm{mol} / \mathrm{C} \mathrm{CoCl}_{2}$, which mimics hypoxia.

EMSA with supershift analysis

EMSA was performed using both the oligonucleotide of the consensus sequence associated with HIF-1 $\alpha$ binding in the HRE on the VEGF gene and, as a negative control, an oligonucleotide with a substitution in the HIF- $1 \alpha$ binding motif (Santa Cruz Biotechnology), as detailed in ESM. Supershift assays were performed as described above, with the exception that, before incubation with the oligonucleotide probes, nuclear extracts were incubated with $5 \mu \mathrm{l}$ TransCrutz gel supershift antibody $(200 \mu \mathrm{g} / \mathrm{ml})$ for $30 \mathrm{~min}$ at room temperature.

The DNA-protein complex was resolved by electrophoresis through $4 \%$ polyacrylamide gel in TBE buffer (Tris$\mathrm{HCl}$, boric acid, EDTA $2 \mathrm{mmol} / \mathrm{l}$, pH 8.0). Gels were subsequently dried and autoradiographed by exposure to X-ray film. Blots were analysed densitometrically using Kodak 1D Image Analysis Software. The density of the different bands was quantified as arbitrary units and changes in protein activity were expressed as percent of control bands. EMSA was carried out using a 6-h VSMC incubation both with $2 \mathrm{nmol} / 1$ insulin and with $200 \mu \mathrm{mol} / 1$ $\mathrm{CoCl}_{2}$ used as a positive control.

\section{HIF-1 $\alpha$ mRNA silencing}

HIF- $1 \alpha$ gene silencing was achieved using $H I F-1 \alpha$ siRNA (target-specific 20-25 nucleotide $s i R N A$, which is designed
Fig. 2 a EMSA showing the ability of a 6-h incubation with $2 \mathrm{nmol} / \mathrm{l}$ insulin to increase HIF$1 \alpha$ binding activity to HRE on the $V E G F$ gene in human aortic $\operatorname{VSMC}(n=4, p=0.0001)$, and in VSMC from Zucker $f a /+$ and $f a /$ $f a$ rats $(n=4 p=0.0001)$. HIF- $1 \alpha$ supershift analysis was carried out for control. b, c Western immunoblotting showing that $H I F-1 \propto$ siRNA inhibits the increase of VEGF and HIF- $1 \alpha$ protein expression induced by an 8 -h incubation with $2 \mathrm{nmol} / \mathrm{l}$ insulin in human (b) and rat (c) VSMC. Blots are representative of four experiments

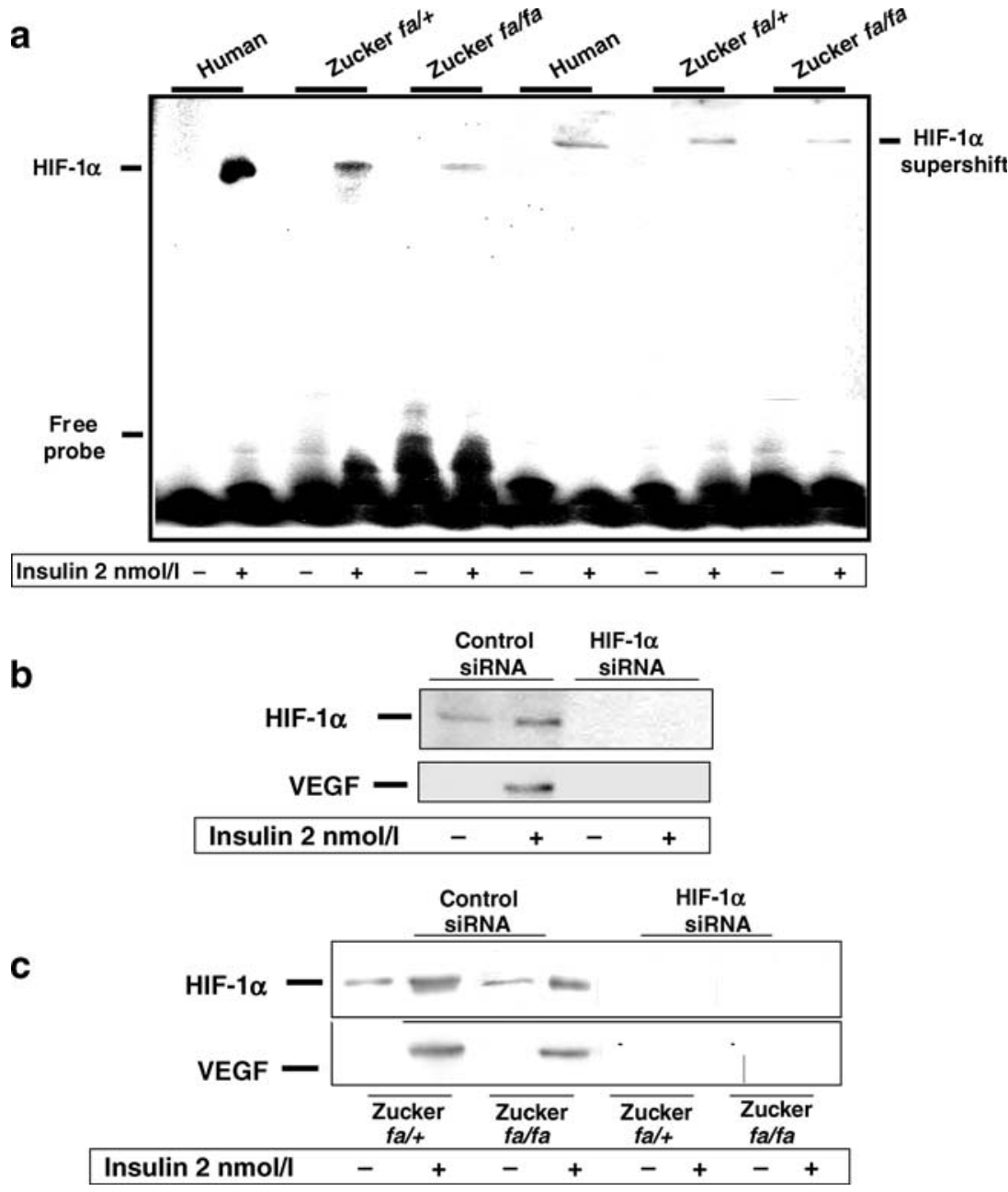


to knockdown HIF-1 $\alpha$ expression) and control siRNA

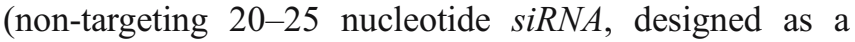
negative control) purchased from Santa Cruz Biotechnology, according to the manufacturer's protocol, as detailed in ESM.

\section{Statistical analysis}

Data in the text and in the figures are expressed as means \pm SEM. Statistical analysis was carried out by ANOVA, and by unpaired Student's $t$-test when only two values had to be compared. A $p$ value of $<0.05$ was considered significant.

\section{Results}

Studies in human aortic VSMC

Time-dependence and concentration-dependence of the insulin effects on HIF-1 $\alpha$ in human aortic VSMC

The purity of the cytosolic and nuclear cellular extracts was confirmed by the fact that $\alpha$-Actin and histone H4 were detectable only in the cytosolic and nuclear extracts, respectively (ESM Fig. 1).
Fig. 3 Western immunoblottings and densitometric analysis showing that in human VSMC the increase of HIF- $1 \alpha$ synthesis induced by $6 \mathrm{~h}$ of incubation with $2 \mathrm{nmol} / \mathrm{l}$ insulin is completely blunted by $60 \mathrm{~min}$ of preincubation with $10 \mu \mathrm{g} / \mathrm{ml}$ cycloheximide, $30 \mu \mathrm{mol} / 1 \mathrm{PD} 98059$, $100 \mu \mathrm{mol} / 1 \mathrm{LY} 294002,30 \mu \mathrm{mol} / 1$ SP600125 and $20 \mathrm{nmol} / 1 \mathrm{rapa}-$ mycin ( $p=0.0001$ vs insulin alone), both in the cytosol (a) and in the nucleus (b). Loading control, $\alpha$-Actin and histone $\mathrm{H} 4$. Open bars, control; closed bars, insulin. Blots are representative of six experiments a
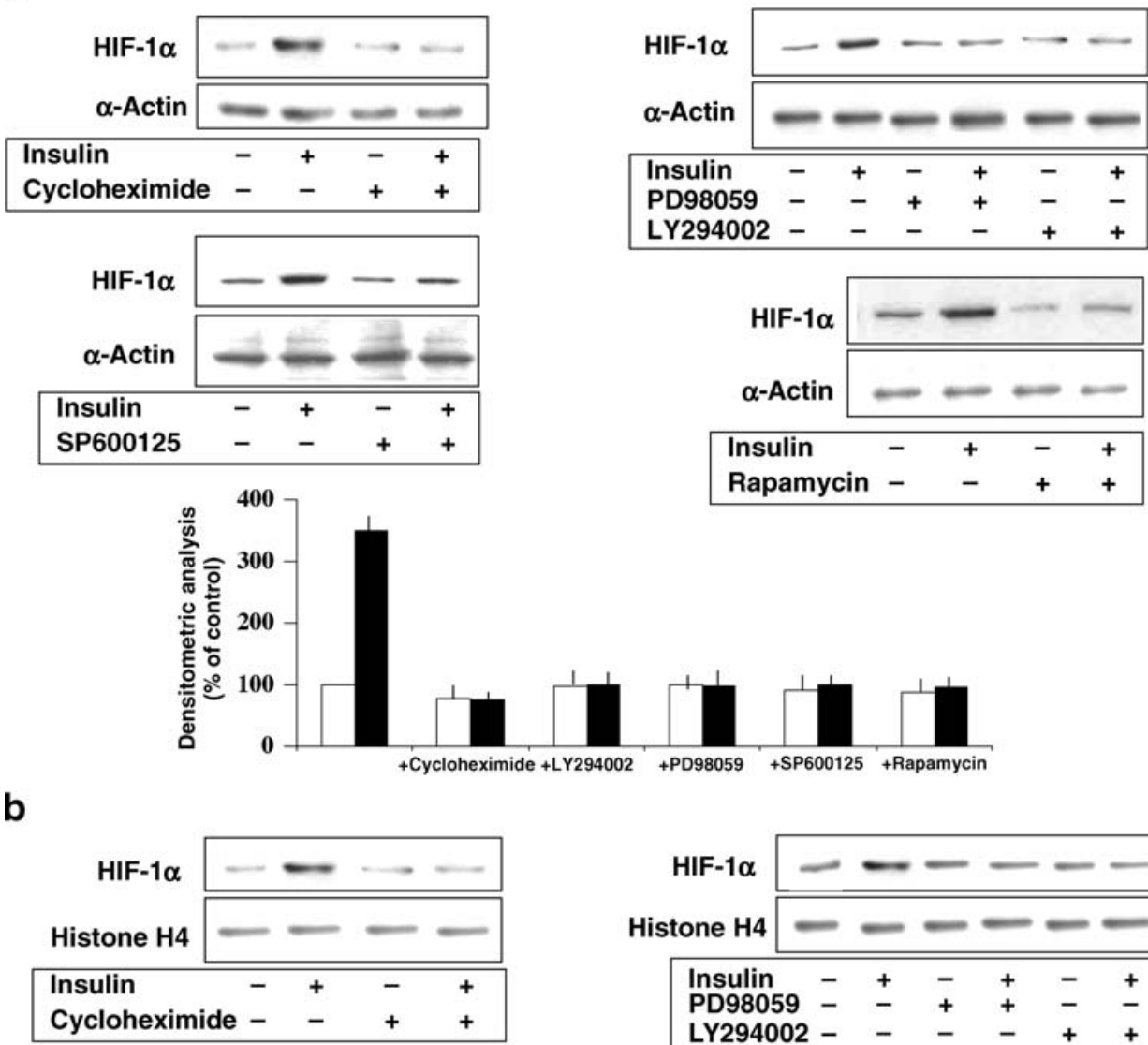

b
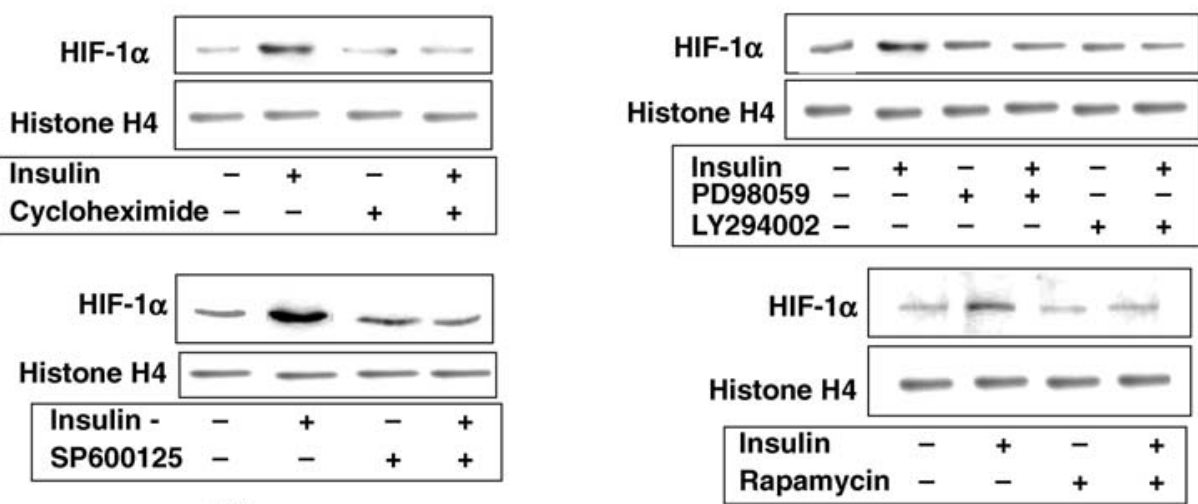

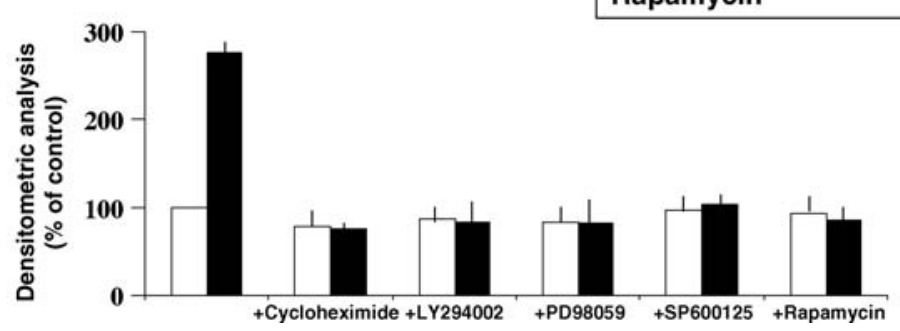


A 6-h incubation with both insulin $(2 \mathrm{nmol} / \mathrm{l})$ and $\mathrm{CoCl}_{2}$ $(200 \mu \mathrm{mol} / \mathrm{l})$ increased cytosolic and nuclear concentration of HIF-1 $\alpha$ (ESM Fig. 1).

Figure 1 shows that incubation with $2 \mathrm{nmol} / 1$ insulin increased HIF- $1 \alpha$ protein content in the cytosol $(n=6$, ANOVA, $\quad p=0.0001)$ and nucleus $(n=6$, ANOVA, $p=0.0001)$. HIF- $1 \alpha$ values at 2,4 and $6 \mathrm{~h}$, both in the cytosol and in the nucleus, were higher than control values $(p=0.0001)$, which did not differ from 0 to $6 \mathrm{~h}$ (data not shown).

Figure 1 shows that a 6-h insulin incubation dosedependently increased HIF- $1 \alpha$ protein content in the cytosol $(n=6$, ANOVA, $p=0.0001)$ and nucleus $(n=6$, ANOVA, $p=0.0001)$. All the insulin doses employed $(0.5,1$ and $2 \mathrm{nmol} / \mathrm{l})$ exerted a significant effect both in the cytosol and in the nucleus $(n=6, p=0.0001)$.

Ability of insulin to influence HIF-1 $\alpha$ binding to the HRE on the VEGF gene and to influence $V E G F$ expression via HIF-1 $\alpha$ in human aortic VSMC

Figure 2a shows that a 6-h incubation of human VSMC with $2 \mathrm{nmol} / 1$ insulin increased HIF-1 $\alpha$ DNA binding activity on the $V E G F$ gene $(n=4, p=0.0001)$. The specificity of HIF- $1 \alpha$ binding to the $V E G F$ gene was confirmed by EMSA supershift assay carried out using an antibody against HIF-1 $\alpha$. These effects could not be detected in the presence of mutant probes (data not shown).

Figure $2 \mathrm{~b}$ shows that the insulin-induced protein expression of $V E G F$ was inhibited by $H I F-1 \propto$ siRNA $(n=4, p=0.0001)$.

Modulation of insulin-induced HIF-1 $\alpha$ synthesis in human aortic VSMC by inhibitors of protein synthesis and of PI3-K/Akt, mTOR, ERK, JNK and $p 38 \mathrm{MAPK}$

Figure 3 shows that the increases of HIF- $1 \alpha$ content both in the cytosol and in the nucleus induced by a 6-h insulin incubation were completely blunted $(n=6)$ by: $(1)$ cycloheximide $(10 \mu \mathrm{g} / \mathrm{ml}) ;(2)$ LY294002 (100 $\mu \mathrm{mol} / \mathrm{l})$; (3)

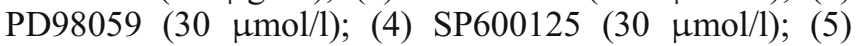
rapamycin $(20 \mathrm{nmol} / \mathrm{l})$; but not by SB203580 $(10 \mu \mathrm{mol} / \mathrm{l})$ ( $p=$ ns vs insulin alone).

\section{Insulin signalling in human aortic VSMC}

Insulin time- and dose-dependently induced phosphorylation of Akt (ANOVA, $p=0.0001, n=6$ ) (Fig. 4 and ESM Fig. 2), ERK-1 and ERK-2 (ANOVA, $p=0.0001$ for both, $n=6$ ) (Fig. 5 and ESM Fig. 3), JNK-1 and JNK-2 (ANOVA, $p=0.0001$ for both, $n=6$ ) (Fig. 5 and ESM Fig. 3) and of the mTOR substrate p70S6K (ANOVA, $p=0.0001, n=6$ ) (Fig. 4 and ESM Fig. 2). a
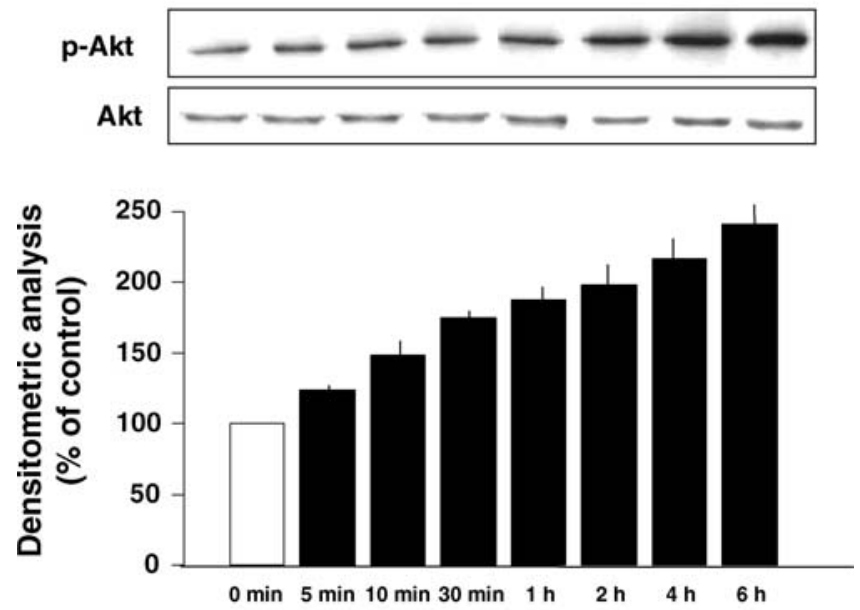

b
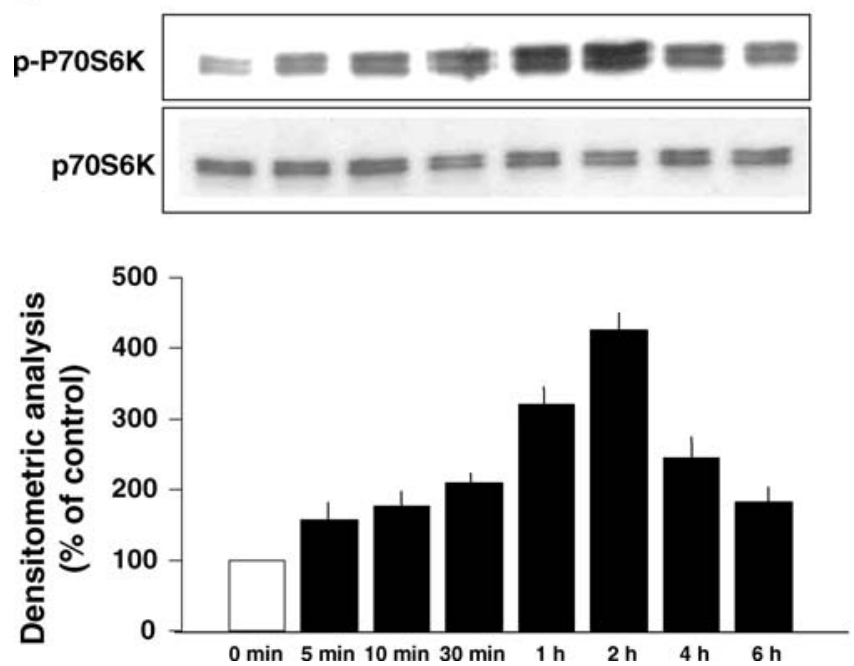

Fig. 4 Western immunoblotting and densitometric analysis showing the time-dependent effects elicited by $2 \mathrm{nmol} / \mathrm{l}$ insulin on a Akt phosphorylation in human VSMC $(n=6$, ANOVA $p=0.0001)$, and b P70S6K phosphorylation in human VSMC $(n=6$, ANOVA $p=0.0001)$. Open bars, control; closed bars, insulin

Studies in aortic VSMC from Zucker $f a /+$ and $f a / f a$ rats

Figure 2a shows that a 6-h incubation of VSMC from Zucker $f a /+$ and $f a / f a$ rats with $2 \mathrm{nmol} / \mathrm{l}$ insulin increased HIF- $1 \propto$ DNA binding activity on the $V E G F$ gene $(n=4$, $p=0.0001$ ), and that this effect was smaller in VSMC from Zucker $f a / f a$ vs those from $f a /+$ rats $(n=4, p=0.0001)$. The specificity of HIF- $1 \alpha$ binding to the VEGF gene was confirmed by EMSA supershift assay. These insulin effects could not be detected in the presence of mutant probes (data not shown).

Figure 2c shows that in VSMC from Zucker $f a /+$ and $f a /$ $f a$ rats the insulin-induced synthesis of VEGF was inhibited by $H I F-1 \alpha \operatorname{siRNA}(n=4, p=0.0001)$. 
Fig. 5 Western immunoblotting and densitometric analysis showing the time-dependent effects elicited by $2 \mathrm{nmol} / \mathrm{l}$ insulin on a ERK-1 and ERK/2 phosphorylation in human VSMC $(n=6$, ANOVA $p=0.0001)$ and b JNK-1 and JNK/2 phosphorylation in human VSMC ( $n=6$, ANOVA $p=0.0001)$. Open bars, control; closed bars, insulin a

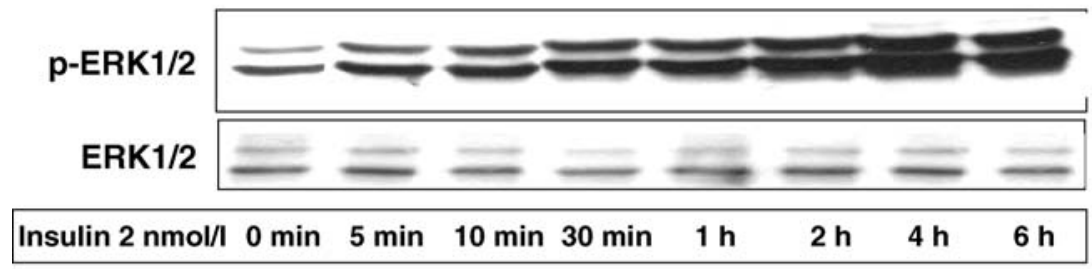

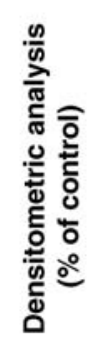

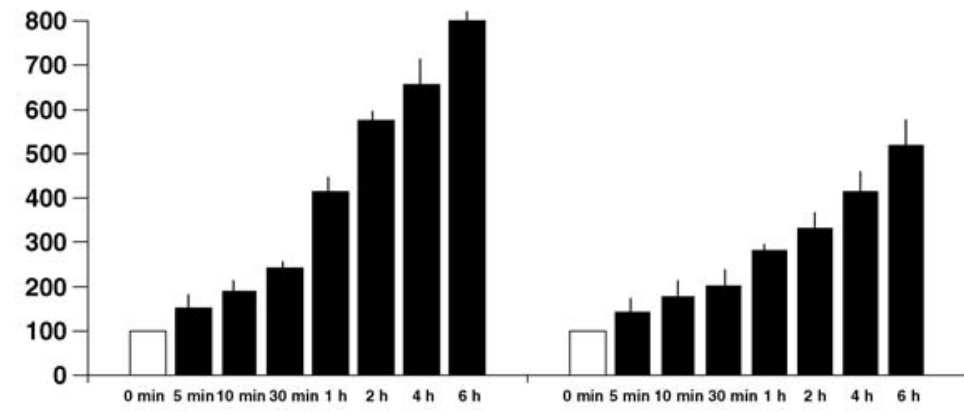

ERK-1

ERK-2

b

JNK 1

JNK 2
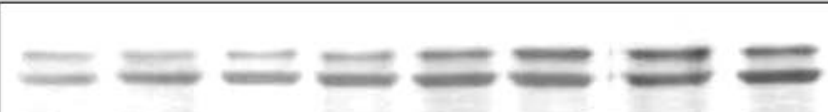

p-JNK 1/2
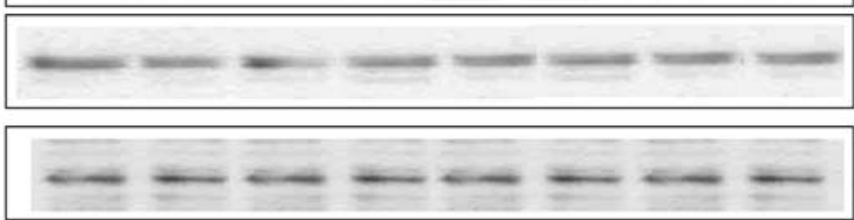

Insulin $2 \mathrm{nmol} / \mathrm{l} \quad 0 \mathrm{~min} \quad 5 \mathrm{~min} 10 \mathrm{~min} 30 \mathrm{~min} \quad 1 \mathrm{~h} \quad 2 \mathrm{~h} \quad 4 \mathrm{~h} \quad 6 \mathrm{~h}$

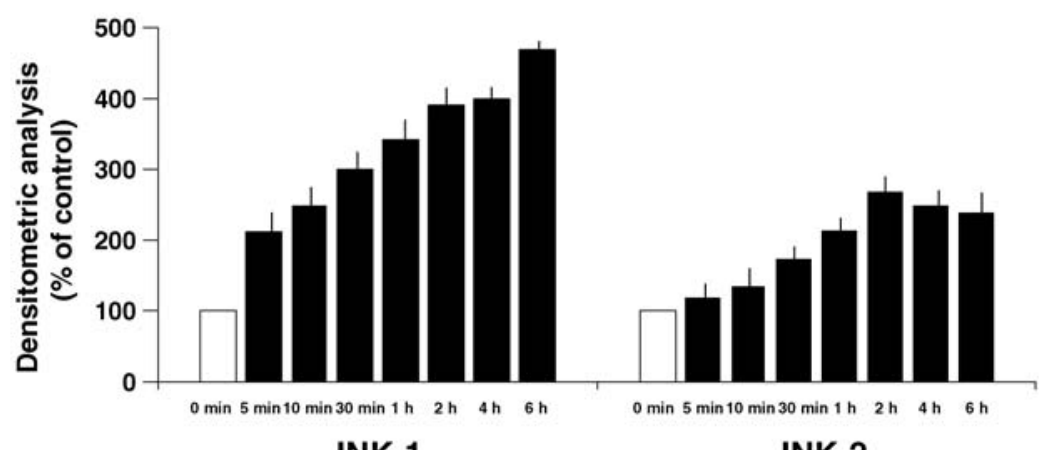

JNK-1
Figures 6 and 7 show that insulin time- and dosedependently increased cytosolic and nuclear content of HIF $-1 \alpha$ in VSMC from Zucker $f a /+$ rats $(n=6$, ANOVA, $p=0.0001)$, each time and dose exerting a significant effect $(n=6, p=0.0001)$.

Even if statistically significant $(n=6$, ANOVA $p=0.0001)$, the time-dependent effects exerted by $2 \mathrm{nmol} /$ 1 insulin on HIF-1 $\alpha$ were lower in VSMC from Zucker $f a /$ $f a$ rats than from Zucker $f a /+$ rats $(p=0.05$ at $2 \mathrm{~h}$ and 0.0001 at 4 and $6 \mathrm{~h}$ in the cytosol, $p=0.0001$ at all the times in the nucleus), whereas baseline HIF-1 $\alpha$ content did not differ.
The dose-dependent insulin effects on HIF- $1 \alpha$, even if statistically significant ( $n=6$, ANOVA $p=0.0001$ ), were lower in VSMC from Zucker $f a / f a$ vs Zucker $f a /+$ rats ( $n=6, p=0.04$ with $0.5 \mathrm{nmol} / 1$ insulin and $p=0.0001$ with 1 and $2 \mathrm{nmol} / 1$ insulin in the cytosol; $p=0.0001$ for all the concentrations in the nucleus).

As previously described in human VSMC, and in VSMC from both Zucker $f a /+$ and $f a / f a$ rats, the insulin effects on cytosolic and nuclear content of HIF-1 $\alpha$ were completely blunted by cycloheximide, LY294002, PD98059, SP600125, and rapamycin (for all the experiments, 
Fig. 6 Western immunoblottings and densitometric analysis showing the time-dependent effects on HIF- $1 \alpha$ protein cytosolic content (a) and nuclear content (b) elicited by $2 \mathrm{nmol} / 1$ insulin incubation for 2, 4 and $6 \mathrm{~h}$ in VSMC from insulinsensitive, lean Zucker $\mathrm{fa} /+$ rats (open bars) ( $n=6$, ANOVA $p=0.0001$ ) and from insulin-resistant Zucker $\mathrm{fa} / \mathrm{fa}$ rats (closed bars) ( $n=6$, ANOVA $p=0.0001)$. At 2, 4 and $6 \mathrm{~h}$ of insulin incubation HIF- $1 \alpha$ concentrations were lower in VSMC from Zucker $f a / f a$ rats, both in the cytosol ( $p=0.05-0.0001)$ and the nucleus ( $p=0.0001)$. Loading control: $\alpha$-Actin and histone $\mathrm{H} 4$. Blots are representative of six experiments a

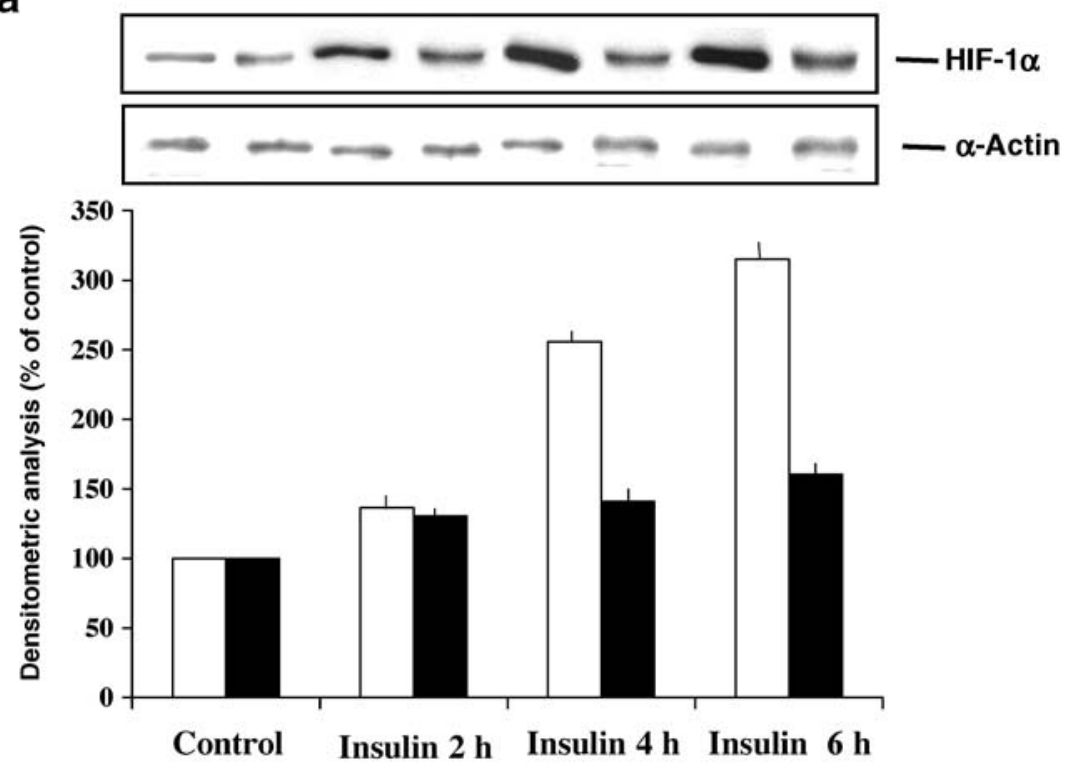

b

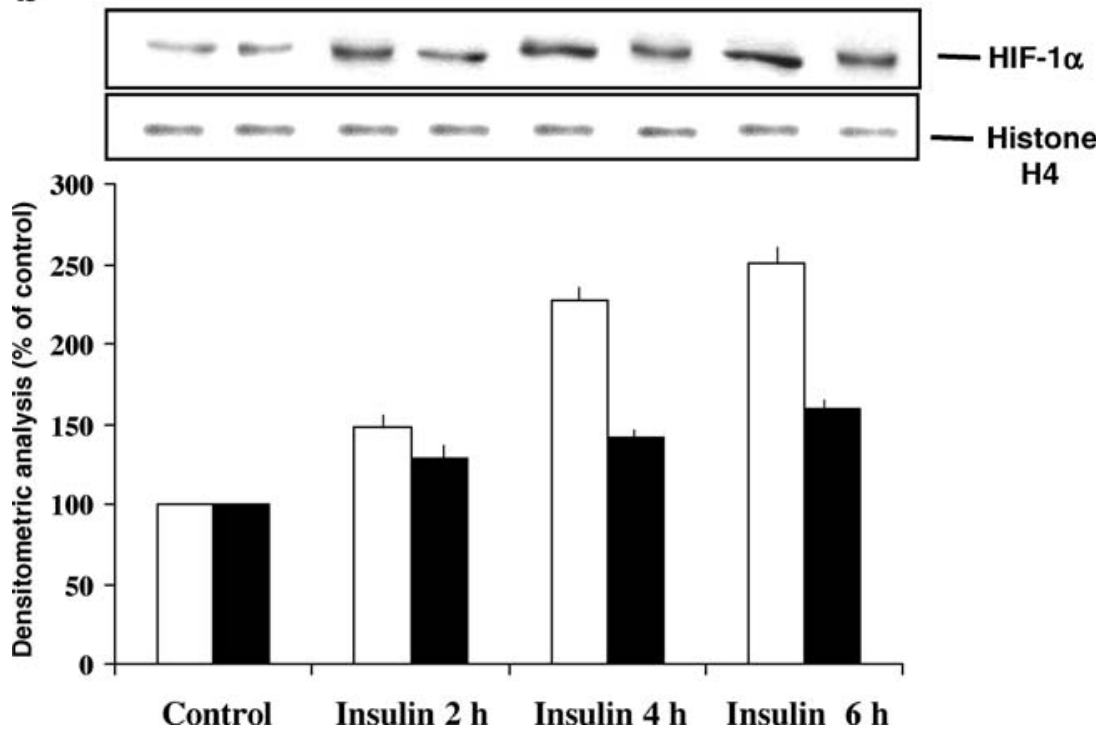

$p=0.0001$ vs insulin alone, $n=6$ ), but not by SB203580 ( $p=$ ns vs insulin alone).

Figure 8 shows that insulin time-dependently induced Akt phosphorylation in VSMC from both Zucker $\mathrm{fa} /+$ (ANOVA, $p=0.0001, n=6$ ) and $f a / f a$ rats (ANOVA, $p=0.0001, n=6)$. These insulin effects, however, were smaller in Zucker $f a / f a$ than $f a /+$ rats at all the incubation times ( $p=0.04$ to $p=0.0001$ ).

Figure 9 shows that insulin time-dependently induced ERK-1 and ERK-2 phosphorylation in VSMC from both Zucker $f a /+$ (ANOVA, $p=0.0001, n=6$ ) and $f a / f a$ rats (ANOVA, $p=0.0001, n=6$ ). These insulin effects, however, were smaller in Zucker $f a / f a$ vs Zucker $f a /+$ rats at all the incubation times $(p=0.01$ to $p=0.0001$ for ERK-1 and $p=0.05$ to $p=0.0001$ for ERK-2).

Figure 10 shows that insulin time-dependently induced JNK-1 and JNK-2 phosphorylation in VSMC from both
Zucker $f a /+$ (ANOVA, $p=0.0001$ for both, $n=6$ ) and $f a / f a$ rats (ANOVA, $p=0.0001$ for both, $n=6$ ). These insulin effects, however, were smaller in Zucker $f a / f a$ rats than Zucker $f a /+$ rats at all the incubation times $(p=0.05$ to $p=0.002$ for JNK-1 and $p=0.05$ to $p=0.0001$ for JNK-2).

In VSMC from both Zucker $f a /+$ and $f a / f a$ rats, insulin effects on signalling molecule phosphorylation were dosedependent $(0.5,1$ and $2 \mathrm{nmol} / \mathrm{l})$ : ANOVA $p=0.0001 \mathrm{for}$ Akt, ERK-1, ERK-2, and p70S6K in Zucker $f a /+$ and fa/fa rats; ANOVA $p=0.0001$ for JNK-1 and JNK-2 in Zucker $f a /+$ rats; ANOVA $p=0.006$ for JNK-1 and 0.007 for JNK-2 in Zucker $f a / f a$ rats.

As far as insulin effects on the mTOR substrate p70S6K phosphorylation are concerned, a similar time-dependent increase was induced by $2 \mathrm{nmol} / \mathrm{l}$ insulin in VSMC from both Zucker $f a /+$ and $f a / f a$ rats (ANOVA, $p=0.0001$ for both, $n=6$ ). 
Fig. 7 Western immunoblottings and densitometric analysis showing the dose-dependent effects on HIF- $1 \alpha$ protein cytosolic content (a) and nuclear content (b) elicited by $6 \mathrm{~h}$ of incubation with $0.5,1$ and $2 \mathrm{nmol} / 1$ insulin in VSMC from insulin-sensitive, lean Zucker fa/+ rats (open bars) $(n=6$, ANOVA $p=0.0001)$ and from insulin-resistant Zucker $f a / f a$ rats (closed bars) $(n=6$, ANOVA $p=0.0001)$. At all insulin doses, HIF-1 $\alpha$ concentrations were lower in VSMC from Zucker $\mathrm{fa} / \mathrm{fa}$ rats, both in the cytosol ( $p=0.04$ to $p=0.0001)$ and the nucleus ( $p=0.0001$ ). Loading control: $\alpha$-Actin and histone $\mathrm{H} 4$. Blots are representative of six experiments a
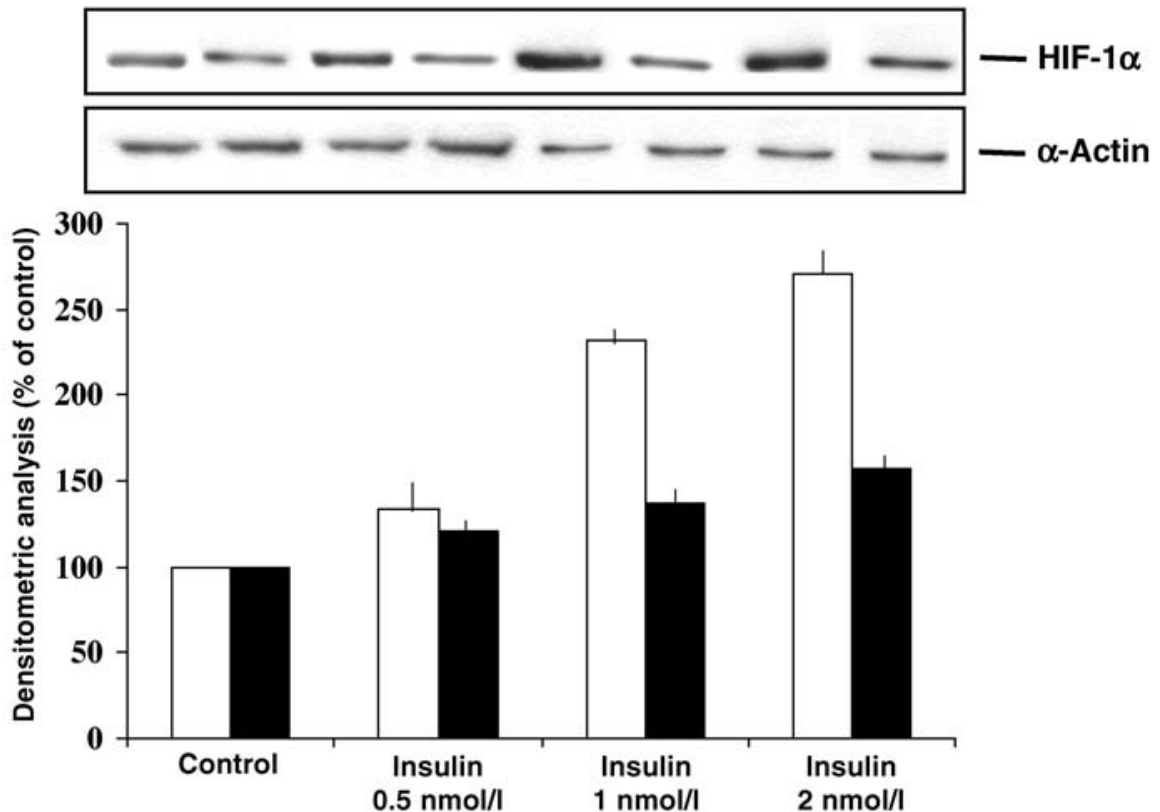

b
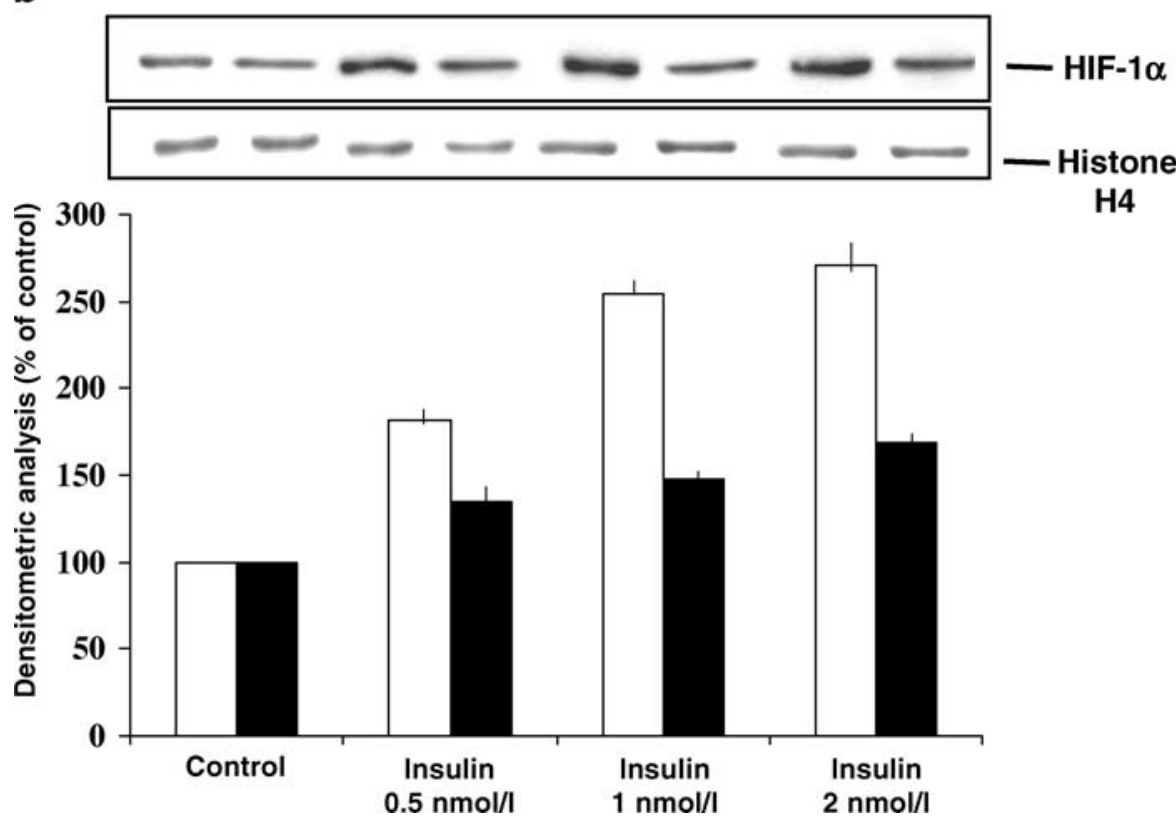

$\mathrm{H} 4$

\section{Discussion}

The present study demonstrates that in aortic VSMC cultured in normoxia insulin increases HIF- $1 \alpha$ protein content in the cytosol and nucleus and that this effect accounts for the insulin-induced increase of VEGF synthesis, as indicated by experiments carried out with EMSA and mRNA silencing techniques. In VSMC, therefore, insulin activates the HIF-1/VEGF pathway, which is deeply involved in new blood vessel formation [18], thus mimicking the action of hypoxia [19-23].

The study also shows that: (1) the insulin-induced increase of HIF- $1 \alpha$ content in cytosol and nucleus is attributable to the increase of HIF- $1 \alpha$ protein synthesis, because it is completely blunted by cycloheximide; and (2) the insulin effects on HIF-1 $\alpha$ are attributable to an interplay between the signalling pathways of PI3-K/Akt and MAPK, both of them exerting a necessary role, because the insulin actions are completely blunted both by PI3-K/Akt and by MAPK inhibitors.

It has already been observed in other cell types such as retinal pigment epithelial cells [10] that insulin regulates HIF- $1 \propto$ through a translation-dependent process. The present study shows that in VSMC the insulin effect is rapid, because a significant increase of HIF- $1 \alpha$ content can be observed after only $2 \mathrm{~h}$ of insulin incubation. Since cycloheximide is a general inhibitor of protein synthesis that is able to affect multiple intracellular processes, it 
Fig. 8 Western immunoblottings and densitometric analysis showing the time-dependent effects on Akt phosphorylation elicited by $2 \mathrm{nmol} / \mathrm{l}$ insulin incubation in VSMC from insulin-sensitive, lean Zucker $\mathrm{fa} /+$ rats $(n=6$, ANOVA $p=0.0001)$ and from insulin-resistant obese Zucker $f a / f a$ rats $(n=6$, ANOVA $p=0.0001$ ). At all incubation times, Akt phosphorylation was lower in VSMC from Zucker $\mathrm{fa}$ / $\mathrm{fa}$ rats than in VSMC from Zucker $f a /+$ rats $(p=0.04$ to $p=0.0001)$. Blots are representative of six experiments. Open bars, control; closed bars, insulin a

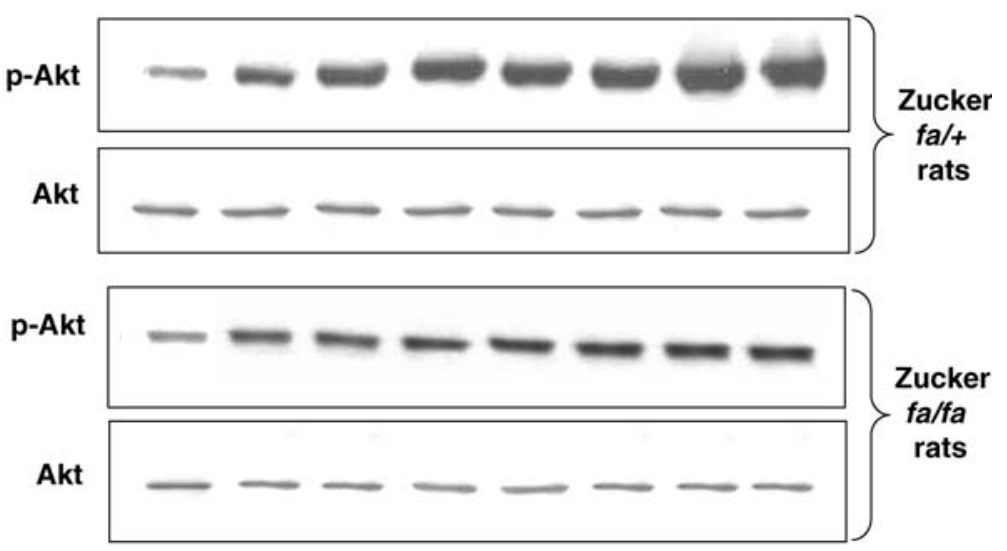

Insulin $2 \mathrm{nmol} / \mathrm{l} 0 \mathrm{~min} 5 \mathrm{~min} 10 \mathrm{~min} 30 \mathrm{~min} 1 \mathrm{~h} \quad 2 \mathrm{~h} \quad 4 \mathrm{~h} \quad 6 \mathrm{~h}$

b

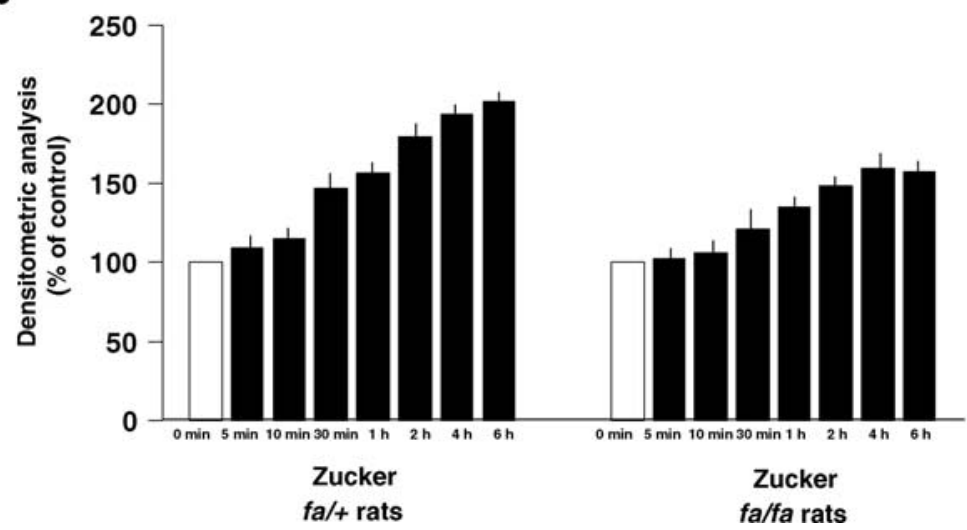

could not be ruled out that the cycloheximide-induced inhibition of the insulin-elicited HIF- $1 \alpha$ synthesis could be exerted by mechanisms that are not entirely related to insulin action.

In addition, this study shows that in VSMC insulin activates signalling pathways that are involved in vasomotion, cell growth and migration, among them the PI3-K/Akt and MAPK pathways [3, 4, 24]. The involvement of both the PI3-K and MAPK pathways in the insulin-induced modulation of HIF- $1 \alpha$ synthesis is not surprising because the same pathways influence the increase of this transcription factor by IGF-1 in colon carcinoma cells [25], and are responsible for the insulin-induced activation of VEGF mRNA [3] and protein [4] expression in VSMC. The MAPK pathway consists of three main parallel cascades: ERK, JNK and p38 MAPK [26]. Our study shows that a role in the insulin-induced HIF- $1 \alpha$ activation is played by ERK and JNK but not by p38 MAPK. JNK is also involved in the HIF- $1 \alpha$ activity increase elicited by hypoxia [27] and growth factors [28] in cancer cells. As far as we know, we are providing here the first evidence that insulin activates JNK in VSMC as it does in skeletal muscle [29], and that $J \mathrm{NK}$ is involved in the insulin-induced increase of HIF-1 $\alpha$ synthesis.

We also showed that insulin induces phosphorylation of the mTOR target molecule p70S6K in cultured human and rat VSMC, and that in the same cells the insulin-induced synthesis of HIF- $1 \alpha$ is blunted by the mTOR inhibitor rapamycin. mTOR involvement in the insulin-induced HIF- $1 \alpha$ increase has been previously described in retinal epithelial cells [10]. mTOR is a serine and threonine protein kinase that plays a role in protein synthesis, cell growth and proliferation, activated by metabolic agents (e.g. amino acids and glucose), cytokines and growth factors, the last acting via the PI3-K/Akt pathway [30]. Furthermore, mTOR plays a pivotal role in the induction of insulin resistance, mainly by downregulation of insulin signalling [30]. In our experimental conditions, insulin elicited a similar degree of phosphorylation in the mTOR substrate p70S6K in VSMC from insulin-sensitive and insulin-resistant rats. Further studies, however, are needed to clarify the complex interrelationships between mTOR and insulin resistance in cultured cells.

Finally, this study revealed that all the insulin effects on HIF- $1 \alpha$ observed in human aortic VSMC also occur in aortic VSMC from the insulin-sensitive, lean Zucker $f a /+$ rats and are deeply impaired in VSMC from insulinresistant obese Zucker $f a / f a$ rats, in which impaired insulininduced synthesis of VEGF is present in the same cells [4]. The results of the present study, therefore, suggest that defects in the insulin-induced activation of HIF- $1 \alpha$ synthesis play a role in the reduced VEGF response to insulin that we previously described in VSMC from Zucker $\mathrm{fa} / \mathrm{fa}$ rats [4]. 
Fig. 9 Western immunoblottings (a) showing the time-dependent effects on ERK-1 and ERK-2 phosphorylation elicited by $2 \mathrm{nmol} / \mathrm{l}$ insulin incubation in VSMC from insulin-sensitive, lean Zucker $\mathrm{fa} /+$ rats and from insulin-resistant obese Zucker fa/fa rats. b, c Densitometric analysis of blots $(n=6$, ANOVA $p=0.0001$ for ERK-1 and ERK-2

[b and c, respectively]). At all the incubation times, ERK-1 and ERK-2 phosphorylation was lower in VSMC from Zucker $\mathrm{fa} / \mathrm{fa}$ rats than in VSMC from Zucker $f a /+$ rats $(p=0.01$ to $p=0.0001$ for ERK-1; $p=0.05$ to $p=0.0001$ for ERK-2). Blots are representative of six experiments. Open bars, control; closed bars, insulin a

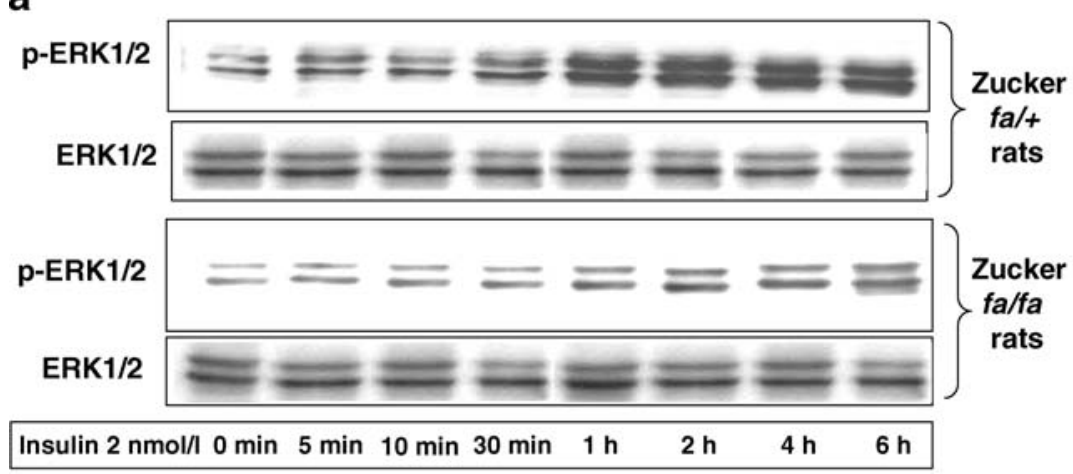

b

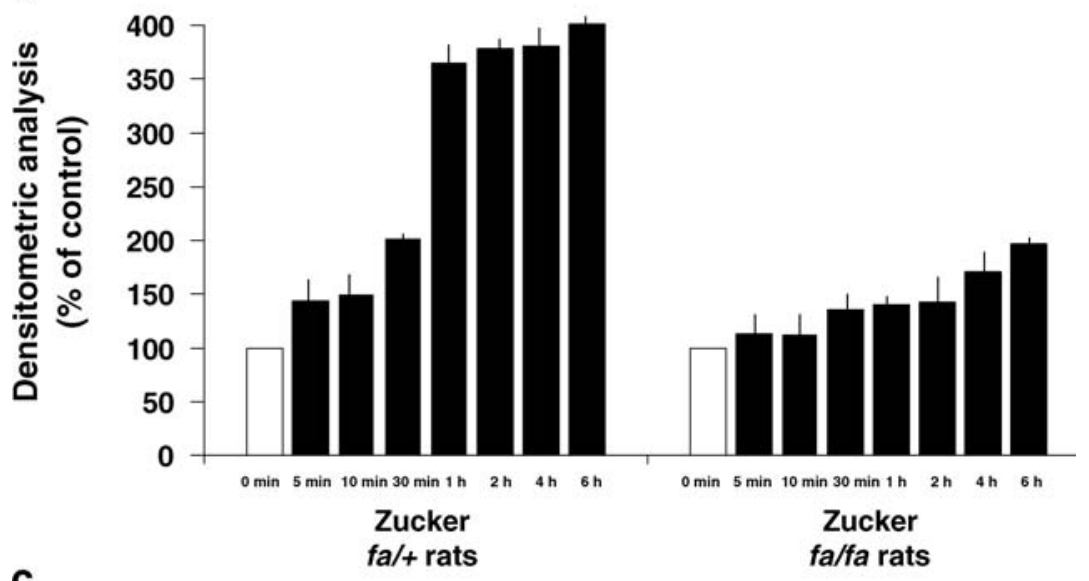

C

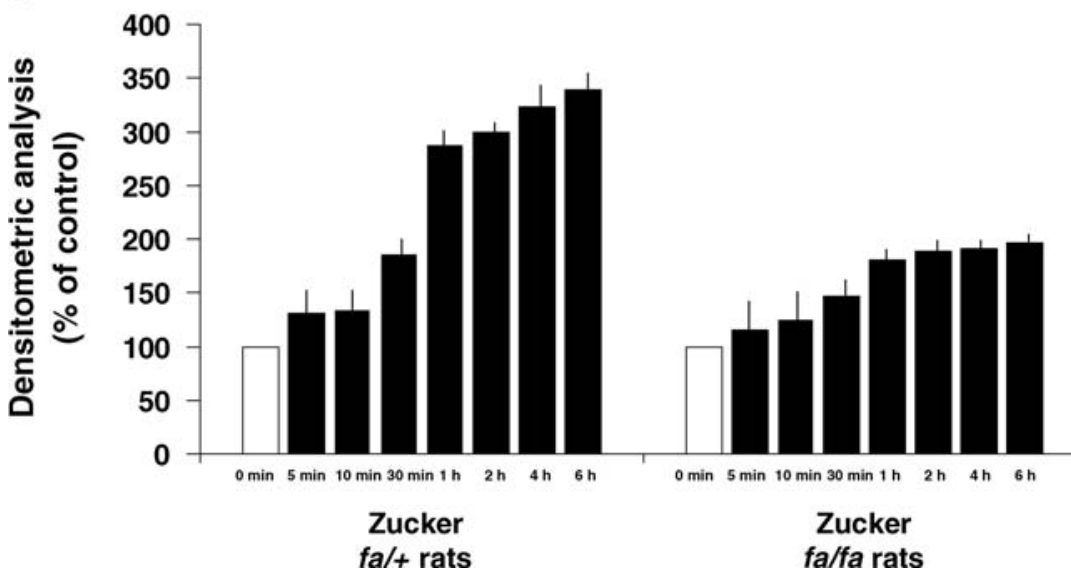

Interestingly, our study shows that in cultured VSMC from insulin-resistant obese Zucker $f a / f a$ rats, not only the insulin-induced PI3-K/Akt pathway activation is significantly impaired, as previously described by us [4], but also the MAPK pathway.

Some reports support the concept that insulin resistance is selective for the PI3-K/Akt pathway [31]. Thus in vascular preparations of obese vs lean Zucker rats, an impaired insulin ability to stimulate the PI3-K pathway in the presence of an intact insulin response of the MAPK pathway has been described in experiments carried out in vivo by infusing insulin with the euglycaemic-hyperinsulinaemic clamp and 'ex vivo' by stimulating intact vessels (aorta and microvessels from the epididymal fat pads) with insulin $2 \mathrm{~h}$ after their isolation [5]. In another report, using skeletal muscle biopsy samples obtained before and after a hyperinsulinaemic-euglycemic clamp in subjects affected by type 2 diabetes mellitus and obesity, the ability of insulin to stimulate the PI3-K pathway was deeply impaired, whereas the insulin effect on the MAPK pathway was normal when compared with biopsy samples obtained from normal lean subjects [32]. Another study observed an impaired increase of Akt phosphorylation and a similar increase of ERK-1/2 phosphorylation in homogenates of cardiac tissues derived from obese vs lean Zucker rats submitted to intravenous insulin infusion before death [33]. 
Fig. 10 Western immunoblottings (a) showing the time-dependent effects on JNK-1 and JNK-2 phosphorylation elicited by $2 \mathrm{nmol} / \mathrm{l}$ insulin incubation in VSMC from insulin-sensitive, lean Zucker $\mathrm{fa} /+$ rats and from insulin-resistant obese Zucker fa/fa rats. b, c Densitometric analysis of blots $(n=6$, ANOVA $p=0.0001$ for JNK-1 and JNK-2 [b and c, respectively]). At all the incubation times, JNK-1 and JNK-2 phosphorylation was lower in VSMC from Zucker $\mathrm{fa}$ $f a$ rats $(p=0.05$ to $p=0.002$ for JNK-1; $p=0.05$ to $p=0.0001$ for JNK-2). Blots are representative of six experiments. Open bars, control; closed bars, insulin a

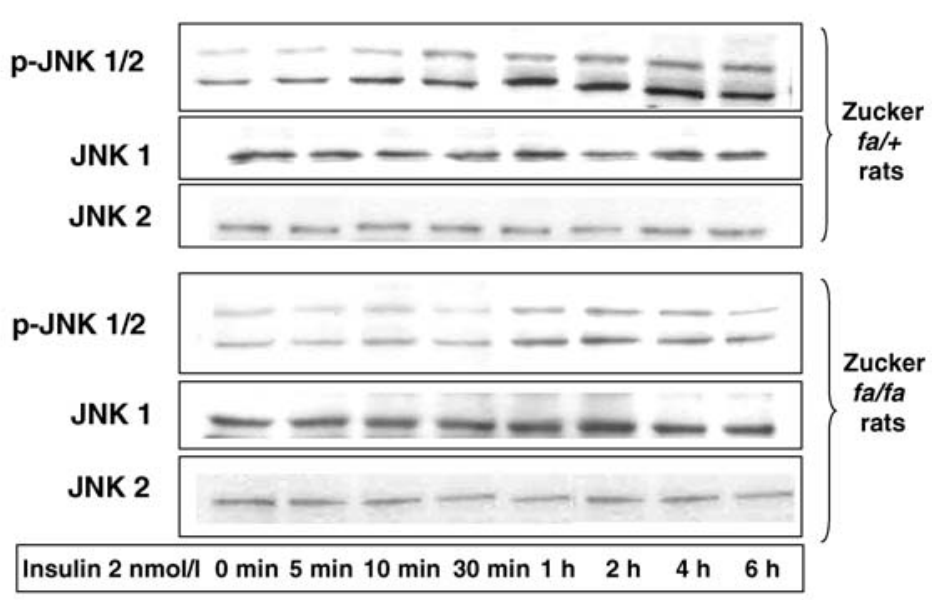

b

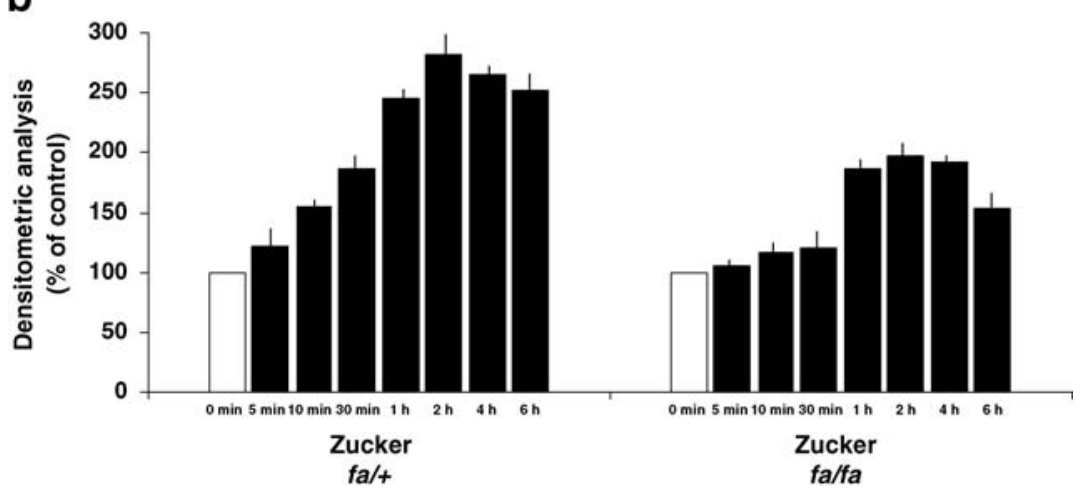

C

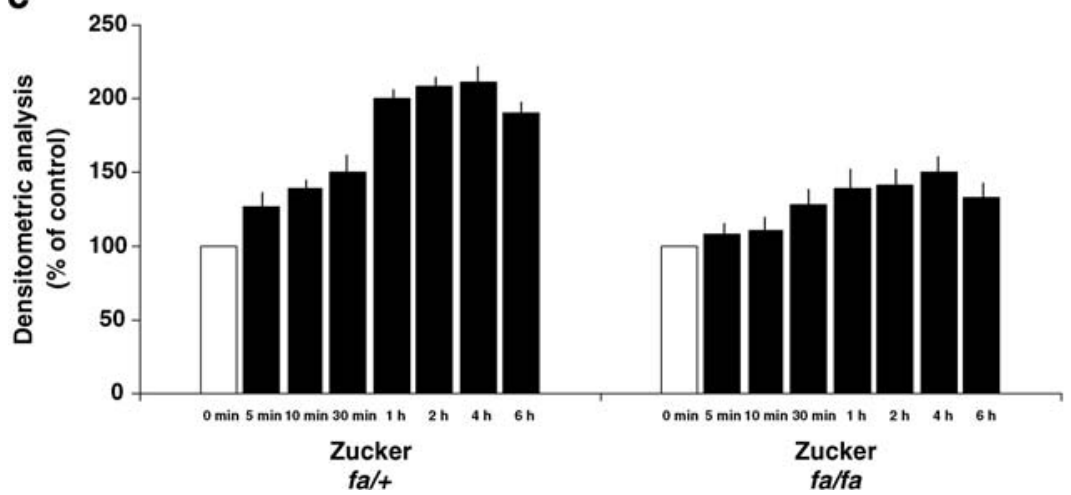

These above-mentioned experiments differed from ours because tissues were exposed to insulin either in vivo [5, $32,33]$ or immediately after death [5], and therefore in a setting deeply influenced by the complex interrelationships of factors affecting insulin sensitivity in vivo (i.e. hormones, growth factors, cytokines, etc.) [34]. Finally, in fibroblast strains obtained from skin biopsy samples from nonobese insulin-resistant subjects vs insulin-sensitive subjects, the effects of insulin on PI3-K phosphorylation were impaired in the presence of a comparable insulin-induced MAPK activation [35].

On the other hand, other papers were unable to demonstrate a selectivity of the insulin resistance for the PI3-K pathway. In particular arterial perfusion of the gastrocnemious muscle with insulin induced a significantly greater ERK-2 activation in lean than in obese Zucker rats [36]; in vitro incubation with insulin of the skeletal muscles extensor digitorum longus and soleus induced a significantly greater phosphorylation of ERK-1/2 and JNK in muscle isolated from lean than in muscle from ob/ob mice [29]; and a 15-min insulin stimulation increased ERK-1/2 and JNK phosphorylation in adipocytes isolated from healthy subjects but not in adipocytes from type 2 diabetic patients [37]. The 'selectivity' of insulin resistance, therefore, appears to be specific for some cell types and strictly dependent on the experimental conditions employed, such as the animal model. For instance, the same group of researchers found a 'selective' insulin resistance 
in skeletal muscle from obese and type 2 diabetic subjects [32] but not in skeletal muscle from Zucker fa/fa rats [36].

To the best of our knowledge, this is the first study to address insulin signalling in cultured VSMC from insulinresistant animals. It shows that insulin-induced activation of both PI3-K and MAPK cascades is impaired. It should be emphasised that we studied pure cultures of VSMC, thus our results cannot be compared with those obtained in vivo or ex vivo in microvessels or aortic preparations of obese Zucker rats [5], not only (as previously mentioned) because of the lack of the environment of cytokines and growth factors existing in vivo, but also because of the lack of endothelial cells which could be the site of 'selective' insulin resistance [38].

In conclusion, our results do not support the existence of a 'selective impairment' of PI3-K signalling in cultured rat VSMC.

Even if the standardised experimental conditions for in vitro experiments on cultured cells do not fully reproduce a physiological setting, the insulin-induced modulation of the HIF-1/VEGF pathway we observed in cultured aortic VSMC can have some consequences in the complex process of new blood vessel formation, which recognises three distinct mechanisms [39]: (1) 'vasculogenesis', occurring mainly in embryonic life; (2) 'angiogenesis', consisting of the sprouting of new capillaries by endothelial cell proliferation and migration, which is able to provide a large increase in capillary bed size but is relatively ineffective in enhancing blood flow in the presence of arterial obstruction; and (3) 'arteriogenesis', i.e. maturation or de novo growth of collateral vessels capable of carrying significant blood flow.

Angiogenesis and arteriogenesis recognise different stimuli. Angiogenesis in adult life is mainly stimulated by tissue hypoxia via activation of HIF- $1 \alpha$, and the consequent transcription of VEGF [39, 40] whereas arteriogenesis is mainly stimulated by haemodynamic factors consequent on the arterial stenosis - such as an increased shear stress - and by accumulation of bloodderived mononuclear cells at the sites of arterial narrowing, resulting in release and production of growth factors [41]. Thus, hypoxia itself plays only a minor role in the stimulation of arteriogenesis, which continues after correction of tissue ischaemia and can occur in tissues that were never ischaemic [42].

In this context, the activation of the HIF-1/VEGF pathway by nonhypoxic mechanisms should be of the greatest interest. The role of endogenous VEGF in arteriogenesis has recently been demonstrated, because VEGF receptor inhibition significantly reduced collateral vessel formation in a mouse model of hindlimb ischaemia [43].

But what is the role of VSMC in this context? Unfortunately, studies concerning the influence exerted by VSMC in angiogenesis and arteriogenesis are rare. It has been recently demonstrated, in a canine model of repetitive coronary occlusion, that intracoronary administration of autologous VSMC transfected with the VEGF gene induces collateral vessel growth [44]. Thus, VSMC are ideal carriers of VEGF to the vessel wall. Together with a few other studies $[14,15,45]$, our investigation demonstrates that VSMC physiologically express HIF-1, and shows that in these cells insulin exerts a clear activating influence in normoxia, allowing us to speculate that it could be involved in the collateral vessel formation.

Furthermore, the deep reduction of the insulin effects on the HIF-1/VEGF pathway we observed in VSMC taken from a well-known animal model of insulin resistance supports the hypothesis that this phenomenon can play a role in the already observed reduction of vascularisation in the insulin-resistant states $[1,2]$.

Clinical medicine shows that a successful development of collateral arteries and new capillaries in ischaemic tissues can prevent myocardial infarction and lead to limb salvage [46], whereas defective angiogenesis and arteriogenesis promote cardiovascular events [47, 48]. It has been proposed that one possible reason for this kind of vascular dysfunction can be the impairment of the growth factor system involved in new vessel formation, the so-called 'growth factor dysfunction' [49].

The reduction of the effects of insulin on the HIF-1/ VEGF pathway in VSMC from an animal model of insulinresistance and obesity could be an aspect of this 'growth factor dysfunction', providing a possible molecular basis for the reduced formation of new vessels in the insulinresistant states $[1,2]$ that probably contributes to the increased prevalence of cardiovascular events observed in obesity [50].

Acknowledgements This study was supported by a grant from the Italian Ministero dell'Istruzione, Università e Ricerca (MIUR) to M. Trovati (Research Project of National Interest-PRINno. 2004060902_004) (local coordinator M. Trovati, National Coordinator, E. Mannarino). Part of this study was presented by G. Doronzo as an oral communication to the ESC Meeting (Munich, August 28 to September 1, 2004) and to the 40th EASD Meeting (Munich, September 5-9, 2004). The EASD-ESC Scholarship was awarded to Gabriella Doronzo.

\section{References}

1. Yilmaz MB, Biyikoglu SF, Akin Y, Guray U, Kisacik HL, Korkmaz S (2003) Obesity is associated with impaired coronary collateral vessel development. Int J Obes Relat Metab Disord 27:1541-1545

2. Chou E, Suzuma I, Way KJ, et al (2002) Decreased cardiac expression of vascular endothelial growth factor and its receptors in insulin-resistant and diabetic states: a possible explanation for impaired collateral formation in cardiac tissue. Circulation 105:373-379

3. Jiang ZY, He Z, King BL, et al (2003) Characterization of multiple signalling pathways of insulin in the regulation of vascular endothelial growth factor expression in vascular cells and angiogenesis. J Biol Chem 278:31964-31971

4. Doronzo G, Russo I, Mattiello L, Anfossi G, Bosia A, Trovati M (2004) Insulin activates vascular endothelial growth factor in vascular smooth muscle cells: influence of nitric oxide and insulin resistance. Eur J Clin Invest 34:664-673

5. Jiang ZY, Lin Y-W, Clemont A, et al (1999) Characterization of selective resistance to insulin signaling in the vasculature of obese Zucker fa/fa rats. J Clin Invest 104:447-457

6. Pugh CW, Ratcliffe PJ (2003) Regulation of angiogenesis by hypoxia: role of the HIF system. Nat Med 9:677-684 
7. Lee JW, Bae SH, Jeong JW, Kim SH, Kim KW (2004) Hypoxia-inducible factor (HIF-1 $\alpha$ ): its protein stability and biological functions. Exp Mol Med 36:1-12

8. Zelzer E, Levy Y, Kahana C, Shilo BZ, Rubinstein M, Cohen B (1998) Insulin induces transcription of target genes through the hypoxia-inducible factor HIF-1 $\alpha /$ ARNT. The EMBO Journal 17:5085-5094

9. Jiang BH, Jiang G, Zheng JZ, Lu Z, Hunter T, Vogt PK (2001) Phosphatidylinositol 3-kinase signalling controls levels of hypoxia-inducible factor 1. Cell Growth Differ 12:363-369

10. Treins C, Giorgetti-Peraldi S, Murdaca J, Semenza GL, Van Obberghen E (2002) Insulin stimulates hypoxia-inducible factor 1 through a phosphatidylinositol 3-kinase/target of rapamycin-dependent signalling pathway. J Biol Chem 277:27975-27981

11. Stiehl DP, Jelkmann W, Wenger RH, Hellwig-Bürgel T (2002) Normoxic induction of the hypoxia-inducible factor- $1 \alpha$ by insulin and interleukin-1 $\beta$ involves the phosphatidylinositol 3-kinase pathway. FEBS Lett 512:157-162

12. Poulaki V, Qin W, Joussen AM, et al (2002) Acute insulin therapy exacerbates diabetic blood-retinal barrier breakdown via hypoxia-inducible factor 1alpha and VEGF. J Clin Invest 109:805-815

13. Treins C, Giorgetti-Peraldi S, Murdaca J, Monthouel-Kartmann MN, Van Obberghen E (2005) Regulation of hypoxia-inducible factor (HIF)-1 activity and expression of HIF hydrolases in response to insulin-like growth factor-1. Mol Endocrinol 19:1304-1317

14. Pagé EL, Robitaille GA, Pouysségur J, Richard DE (2002) Induction of hypoxia-inducible factor- $1 \alpha$ by transcriptional and translational mechanisms. J Biol Chem 277:48403-48409

15. Richard DE, Berra E, Pouysségur J (2000) Nonhypoxic pathway mediates the induction of hypoxia-inducible factor$1 \alpha$ in vascular smooth muscle cells. J Biol Chem 275: 26765-26771

16. Scott-Burden T, Resnik TJ, Hahn AWA, Baur U, Box RJ, Buhler FR (1989) Induction of growth-related metabolism in human vascular muscle cells by low density lipoprotein. J Biol Chem 264:12582-12589

17. Trovati M, Massucco P, Mattiello L, et al (1999) Human vascular smooth muscle cells express a constitutive nitric oxide synthase that insulin rapidly activates, thus increasing guanosine $3^{\prime}: 5^{\prime}$-cyclic monophosphate and adenosine 3':5'-cyclic monophosphate concentrations. Diabetologia 42:831-839

18. Khatri JJ, Johnson C, Magid R, et al (2004) Vascular oxidant stress enhances progression and angiogenesis of experimental atheroma. Circulation 109:520-525

19. Levy AP, Levy NS, Wegner S, Goldberg MA (1995) Transcriptional regulation of rat vascular endothelial growth factor gene by hypoxia. J Biol Chem 270:13333-13340

20. Stein I, Neeman M, Shweiki D, Itin A, Keshet E (1995) Stabilization of vascular endothelial growth factor mRNA by hypoxia and hypoglycemia and coregulation with other ischemia-induced genes. Mol Cell Biol 15:5363-5368

21. Wang GL, Semenza GL (1993) Characterization of hypoxiainducible factor 1 and regulation of DNA binding activity by hypoxia. J Biol Chem 268:21513-21518

22. Semenza GL (2000) HIF-1: mediator of physiological and pathophysiological response to hypoxia. J Appl Physiol $88: 1474-1480$

23. Ferrara N (2001) Role of vascular endothelial growth factor in regulation of physiological angiogenesis. Am J Cell Physiol 280:C1358-1366

24. Wang CC, Gurevich I, Draznin B (2003) Insulin affects vascular smooth muscle cell phenotype and migration via distinct signalling pathways. Diabetes 52:2562-2569

25. Fukuda R, Hirota K, Fan F, Jung YD, Ellis LM, Semenza GL (2002) Insulin-like growth factor 1 induces hypoxia-inducible factor 1-mediated vascular endothelial growth factor expression, which is dependent on MAP kinase and phosphatidylinositol 3-kinase signalling in colon cancer cells. J Biol Chem $227: 38205-38211$
26. Widmann C, Gibson S, Jarpe MB, Johnson GL (1999) Mitogen activated protein kinase: conservation of three kinase module from yeast to human. Physiol Rev 79:143-180

27. Comeford KM, Cummins EP, Taylor CT (2004) C-Jun $\mathrm{NH}_{2-}$ terminal kinase activation contributes to hypoxia-inducible factor $1 \alpha$-dependent $P$-glycoprotein expression in hypoxia. Cancer Res 64:9057-9061

28. Tacchini L, Matteucci E, De Ponti C, Deserio MA (2003) Hepatocyte growth factor signalling regulates transcription of genes belonging to the plasminogen activation system via hypoxia inducible factor-1. Exp Cell Res 1:391-401

29. Leng Y, Steiler TL, Zierath JR (2004) Effects of insulin, contraction, and phorbol ester on mitogen-activated protein kinase signalling in skeletal muscle from lean and ob/ob mice. Diabetes 53:1436-1444

30. Manning BD (2004) Balancing Akt with S6K: implications for both metabolic diseases and tumorigenesis. J Cell Biol 167:399-403

31. Wang CL, Goalstone ML, Draznin B (2004) Molecular mechanisms of insulin resistance that impact cardiovascular biology. Diabetes 53:2735-2740

32. Cusi K, Maezono K, Osman A, et al (2000) Insulin resistance differentially affects the PI3-kinase- and MAP kinase-mediated signalling in human muscle. J Clin Invest 105:311-320

33. Carvalheira JBC, Calegari VC, Zecchin HG, et al (2003) The cross-talk between angiotensin and insulin differentially affects phosphatidylinositol 3-kinase- and mitogen-activated protein kinase-mediated signalling in rat heart: implications for insulin resistance. Endocrinology 144:5604-5614

34. Kryriakis JM, Avruch J (2001) Mammalian mitogen-activated protein kinase signal transduction pathways activated by stress and inflammation. Physiol Rev 81:807-869

35. Pandolfi A, Solini A, Pellegrini G, et al (2005) Selective insulin resistance affecting nitric oxide release but not PAI-1 synthesis in fibroblast from insulin-resistant individuals. Arterioscler Throm Vasc Biol 25:2392-2397

36. Osman AA, Hancock J, Hunt DG, Ivy JL, Mandarino LJ (2001) Exercise training increases ERK2 activity in skeletal muscle of obese Zucker rats. J Appl Physiol 90:454-460

37. Carlson CJ, Koterski S, Sciotti RJ, Poccard GB, Rondinone CM (2003) Enhanced basal activation of mitogen-activated protein kinase in adipocytes from type 2 diabetes. Diabetes 52:634-641

38. Potenza MA, Marasciulo FL, Chieppa DM, et al (2005) Insulin resistance in spontaneously hypertensive rats is associated with endothelial dysfunction characterized by imbalance between NO and ET-1 production. Am J Physiol Heart Circ Physiol 289 (2):H813-H822

39. Carmeliet P (2000) Mechanisms of angiogenesis and arteriogenesis. Nat Med 6:389-395

40. Risau W (1997) Mechanisms of angiogenesis. Nature 386: 671-674

41. Heil M, Schaper W (2004) Pathophysiology of collateral development. Coron Artery Dis 15:373-378

42. De Muinck ED, Simons M (2004) Re-evaluating therapeutic neovascularization. J Mol Cell Cardiol 36:25-32

43. Babiak A, Schumm AM, Wangler C, et al (2004) Coordinated activation of VEGFR-1 and VEGFR-2 is a potent arteriogenic stimulus leading to enhancement of regional perfusion. Cardiovasc Res 61:789-795

44. Hattan N, Warltier D, Gu W, Kolz C, Chilian WM, Weihrauch D (2004) Autologous vascular smooth muscle cell-based myocardial gene therapy to induce coronary collateral growth. Am J Physiol Heart Circ Physiol 287:H488-493

45. Hodges YK, Reese SM, Pahl PM, Horwitz LD (2005) Paradoxical effects of iron chelation on growth of vascular endothelial cells. J Cardiovasc Pharmacol 45:539-544

46. Yla-Herttuala S, Markkanen JE, Rissanen TT (2004) Gene therapy for ischemic cardiovascular diseases: some lessons learned from the first clinical trials. Trends Cardiovasc Med $14: 295-300$ 
47. Habib GB, Heibig J, Forman SA, et al (1991) Influence of coronary collateral vessels on myocardial infarct size in humans, results of phase 1 thrombolysis in myocardial infarction (TIMI) trial. The TIMI investigators. Circulation 83:739-746

48. Hansen JF (1989) Coronary collateral circulation, clinical significance and influence on survival in patients with coronary artery disease. Am Heart J 117:290-295
49. Waltenberger J (2005) Growth factor signal transduction defects in the cardiovascular system. Cardiovasc Res 65:574580

50. Jonsson S, Hedblad B, Engstrom G, Nilsson P, Berglund G, Janzon L (2002) Influence of obesity on cardiovascular risk. Twenty-three year follow-up of 22,025 men from an urban Swedish population. Int J Obes Relat Metab Disord 26: 1046-1053 